\title{
CLINICAL RESULTS OF MITRAL VALVE REPAIR BY RECONSTRUCTING ARTIFICIAL CHORDAE TENDINEAE IN CHILDREN
}

\author{
Takashi Matsumoto, MD \\ Hideaki Kado, $\mathrm{MD}^{\mathrm{a}}$ \\ Munetaka Masuda, MDa \\ Yuichi Shiokawa, MD \\ Kouji Fukae, MD \\ Shigeki Morita, $\mathrm{MD}^{\mathrm{b}}$ \\ Hisataka Yasui, $\mathrm{MD}^{\mathrm{b}}$
}

\begin{abstract}
Objective: There are an increasing number of reports concerning mitral valve repair by reconstructing the chordae tendineae with the use of expanded polytetrafluoroethylene sutures in adults. However, little information is available about application or results of this technique in children. Methods: Between January 1995 and December 1997, 16 children who had from moderate to severe mitral regurgitation mainly as the result of a prolapse of the anterior leaflet (age range, 5 months-12.8 years) underwent mitral valve repair by reconstruction of artificial chordae. Either unilateral or bilateral Kay-Reed annuloplasty was also performed to correct annular dilatation in all patients. Results: No operative death or morbidity was observed. Before discharge, immediate postoperative echocardiography showed less than trivial mitral regurgitation in all patients. The follow-up was complete in all cases by a clinical examination and serial echocardiograms, and the median follow-up period was 14.8 months (range, 1.3-26.4 months). There were no valverelated events during the entire follow-up period. The degree of mitral regurgitation, estimated by echocardiography performed at recent follow-up period, was none in $\mathbf{5}$ patients, trivial in 10 patients, and mild in 1 patient. The diastolic and systolic dimensions of the left ventricle decreased and were $95.0 \%$ and $96.2 \%$ of the normal values, respectively. Conclusions: Although further investigations and long-term results are still called for, mitral valve repair by reconstruction of the artificial chordae was found to be safe and effective even in infants and children. (J Thorac Cardiovasc Surg 1999;118:94-8)
\end{abstract}

A lthough the results of mitral valve repair for valve A incompetence in children are generally acceptable, ${ }^{1-5}$ the results of the repair of a prolapsed anterior leaflet in children by conventional methods is unsatisfactory and reoperation or mitral valve replacement (MVR) is inevitable in some patients. ${ }^{3,6}$ However, the required anticoagulation regimen tends to be cumbersome and troublesome in small children. In addition, the somatic growth of the patient often requires a rereplacement of the mitral valve prosthesis.

From the Department of Cardiovascular Surgery, Fukuoka Children's Hospital, ${ }^{\mathrm{a}}$ and the Department of Cardiac Surgery, Faculty of Medicine, Kyushu University, ${ }^{\text {b }}$ Fukuoka, Japan.

Received for publication Aug 25, 1998; revisions requested Nov 17, 1999; revisions received March 1, 1999; accepted for publication March 2, 1999.

Address for reprints: Hideaki Kado, MD, Head Doctor, Department of Cardiovascular Surgery, Fukuoka Children's Hospital, 2-5-1 Tojin-machi Chuo-ku, Fukuoka, 810, Japan.

Copyright (C) 1999 by Mosby, Inc.

$0022-5223 / 99 \$ 8.00+0 \quad \mathbf{1 2 / 1 / 9 8 4 3 6}$
Recently, there has been increasing interest in the repair of the mitral valve by the reconstruction of the chordae tendineae with the use of expanded polytetrafluoroethylene (ePTFE) sutures in adult patients. The effectiveness and reliability of this technique has also been shown both experimentally ${ }^{8}$ and clinical-

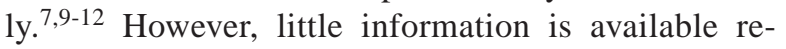
garding its application and results in children. We therefore present our 2-year experience in performing artificial chorda reconstruction of the mitral valve in children and also discuss the usefulness of its early application.

\section{Patients and methods}

Patients. From January 1995 through December 1997, 16 children who had mitral regurgitation (MR) underwent mitral valve repair by reconstruction of the chordae tendineae with the use of ePTFE sutures at Fukuoka Children's Hospital. The patient ages ranged from 5 months to 12 years (median, 3.6 years). The body weight ranged from 3.9 to $30.4 \mathrm{~kg}$ (median, $11.3 \mathrm{~kg}$ ). Six patients had also undergone previous operations that included Blalock-Taussig shunt (1 patient), Brock's pro- 
Volume 118, Number 1

Table I. Patient profiles

\begin{tabular}{|c|c|c|c|c|c|}
\hline Patient & Sex & $\begin{array}{l}\text { Age } \\
(y)\end{array}$ & $\begin{array}{c}\text { Body weight } \\
(\mathrm{kg})\end{array}$ & Associated lesions & Concomitant procedures \\
\hline 1 & $\mathrm{~F}$ & 0.43 & 3.9 & VSD, PDA, AS & Closure of VSD, PDA ligation \\
\hline 2 & $\mathrm{~F}$ & 1.4 & 8.9 & VSD & Closure of VSD \\
\hline 3 & $\mathrm{~F}$ & 1.4 & 9.5 & Anomalous origin of LCA from PT & Translocation of LCA \\
\hline 4 & M & 1.7 & 9.1 & VSD, DCRV & Closure of VSD, RVOTR \\
\hline 5 & $\mathrm{~F}$ & 2 & 9.4 & VSD & Closure VSD \\
\hline 6 & $\mathrm{~F}$ & 2.2 & 7.5 & ASD & Closure of ASD \\
\hline 7 & $\mathrm{~F}$ & 2.8 & 9.2 & $\mathrm{TA}, \mathrm{PA}$ & TCPC, patch plasty of pulmonary artery \\
\hline 8 & $\mathrm{~F}$ & 3.5 & 13 & $(-)$ & $(-)$ \\
\hline 9 & $\mathrm{~F}$ & 3.7 & 9.3 & PA, PDA, ASD & BCPS, PDA ligation \\
\hline 10 & $\mathrm{~F}$ & 4.6 & 13.7 & CAVSD, TR & Tricuspid valvuloplasty and annuloplasty \\
\hline 11 & $\mathrm{~F}$ & 5.2 & 15.8 & Double aortic arch & Repair of double aortic arch \\
\hline 12 & $\mathrm{~F}$ & 5.8 & 15.8 & Anomalous origin of LCA from PT & Translocation of LCA \\
\hline 13 & M & 9.4 & 17.4 & ASD & Closure of ASD \\
\hline 14 & $\mathrm{~F}$ & 10.8 & 22.0 & $(-)$ & $(-)$ \\
\hline 15 & M & 11.1 & 30.4 & $(-)$ & $(-)$ \\
\hline 16 & $\mathrm{~F}$ & 12.8 & 28.6 & $(-)$ & $(-)$ \\
\hline
\end{tabular}

$V S D$, Ventricular septal defect; $P D A$, patent ductus arterious; $A S$, aortic valve stenosis; $L C A$, left coronary artery; $P T$, pulmonary trunk; $D C R V$, double-chambered right ventricle; $R V O T R$, right ventricle outflow tract reconstruction; $A S D$, atrial septal defect; $T A$, tricuspid atresia; $P A$, pulmonary atresia; $T C P C$, total cavopulmonary connection; $B C P S$, bidirectional cavopulmonary shunt; CAVSD, complete form of atrioventricular septal defect; $T R$, tricuspid valve regurgitation.

cedure (1 patient), complete repair of an atrioventricular septal defect (1 patient), closure of an atrial septal defect (1 patient), and closure of ventricular septal defects (2 patients). All except 4 patients had associated cardiovascular malformations; 12 patients underwent concomitant procedures (Table I). Only 1 patient (who had received a complete repair of an atrioventricular septal defect) had undergone any previous mitral valve operation.

Assessment of MR was performed by transthoracic Doppler echocardiography. Thus there was no MR if no abnormal systolic flow was detected; trivial MR if the systolic flow was localized immediately posterior to the mitral valve; mild MR when the systolic flow was recorded at a wider area posterior to the mitral valve, but was absent when the beam was directed toward the aortic root and the mitral valve disappeared from view; moderate MR when the area of the systolic flow was present well posterior to the mitral valve reaching the anterior half of the atrial cavity; and severe MR when the flow was present diffusely all over the left atrium. Preoperative assessment of MR showed it to be moderate in 13 patients and severe in 3 patients. On the basis of the echocardiographic result, prolapse of the anterior mitral leaflet was considered to be the main cause of MR in all patients. A dilatation of the left ventricular cavity (mean left ventricular diastolic dimension [LVDd], $128 \% \pm 4 \%$ of normal; and mean left ventricular systolic dimension [LVDs], $127 \% \pm 5 \%$ of normal along with the dilation of mitral anulus dimension assessed in the long axis view [Z-value, $3.6 \pm$ 0.6]) were found in all patients. The normal size of LVDd, LVDs, and mitral valve Z-score were calculated from body surface area according to the publications of Fukushige ${ }^{13}$ and Kirklin and Barratt-Boyes. ${ }^{14}$ Preoperative cardiac catheterization was performed in all patients (interval range, 0.1-20.5 months; median, 6.7 months). All patients were in normal sinus rhythm before the operation.

Operative technique. The approach to the heart was through a midline sternotomy, and the intracardiac repair was performed with standard cardiopulmonary bypass with moderate hypothermia. Myocardial protection was provided by topical cooling and intermittent cold crystalloid cardioplegic solution.

Approaches to the mitral valve were either through a left atriotomy (12 patients) or transseptal (4 patients) in the patients with an atrial septal defect. The entire mitral valve apparatus was carefully inspected, and cold cardioplegic solution was routinely injected into the left ventricular cavity to test for valve competence and to assess leaflet motion and coaptation. Prolapse of the anterior leaflet was found in all 16 patients. The main cause of prolapse was chordal elongation in 7 patients, torn chordae in 4 patients, absence of chordae in 3 patients, and papillary muscle dysfunction in 2 patients.

Subsequently, we reconstructed the chordae tendineae with 4-0 or 5-0 (in patients less than 2 years old) ePTFE sutures using the following unique techniques (Fig 1). At first, a double-armed mattress ePTFE suture was passed through the free prolapsed edge from the ventricular side to the atrial side. These 2 ends were then passed through the papillary muscle at 3 to $4 \mathrm{~mm}$ from its top, drawing the free edge down to the entry point on the papillary muscle of the 2 ends of the suture. The sutures were passed through a pledget, which would be on the side where the sutures emerged from the papillary muscle. There was no pledget on the side of the muscle where the sutures entered. The knot was then tied at the level of the opposing normal leaflet. The new chorda was then pulled back through the papillary muscle until the pledget came up 

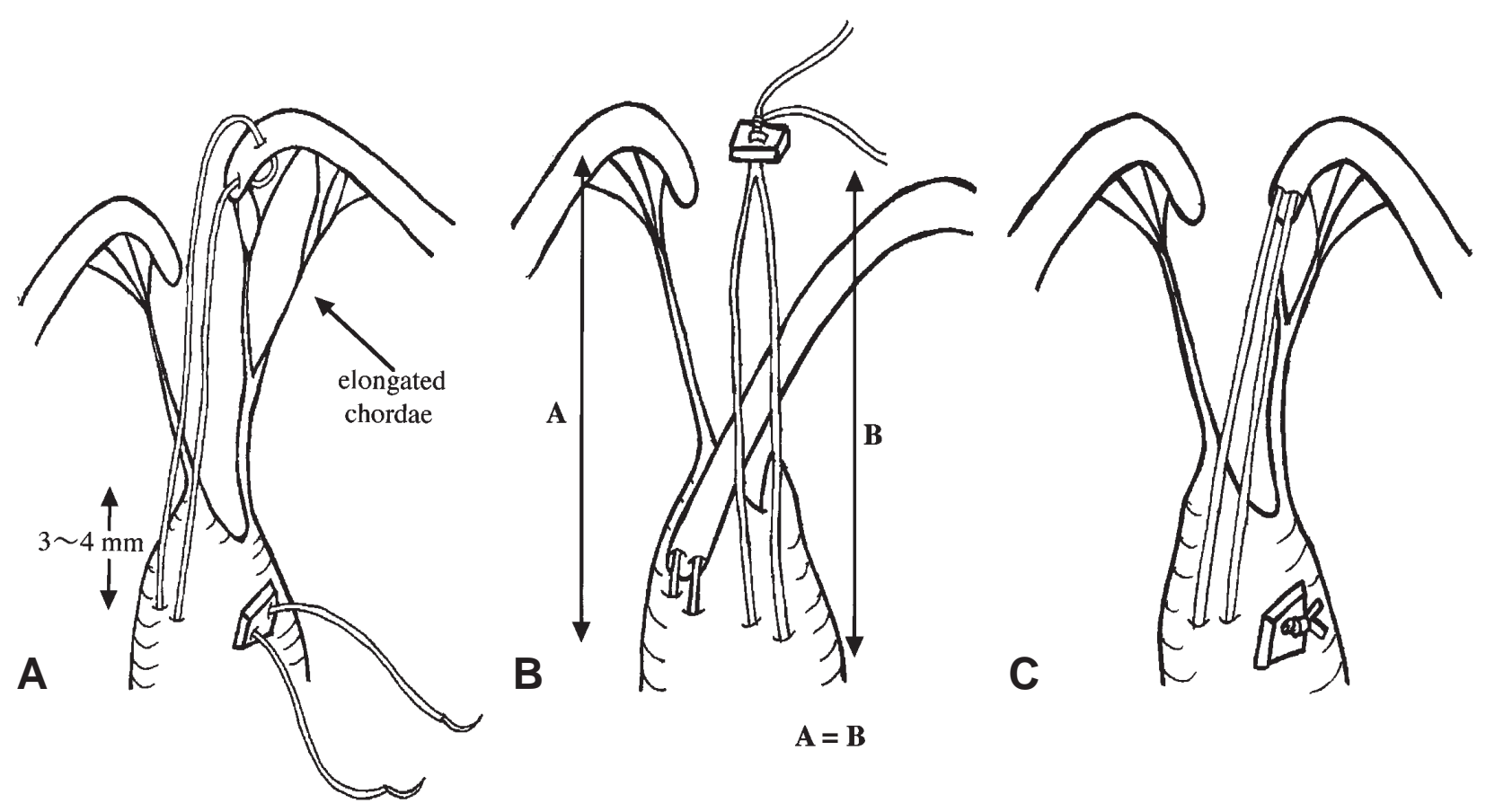

$\mathbf{A}=\mathbf{B}$

Fig 1. The technique of mitral valve repair by reconstructing chordae with ePTFE sutures. A, A double-armed ePTFE suture was passed through the rough zone of the prolapsed leaflet and through papillary muscle at 3 to 4 $\mathrm{mm}$ from its top. The sutures were then passed through a pledget on the side of the muscle, where the sutures emerged from the papillary muscle. B. This suture was drawn until the leaflet was drawn to the papillary muscle. The knot was then tied at the level of the opposing normal leaflet. $A$ is the distance from the chordal origin to the free edge of opposite cusp; $B$ is the length of reconstructing chordae. $\mathbf{C}$, The new chordae were then pulled back through the papillary muscle until the pledget came up against the muscle.

Table II. Degree of MR before the mitral valve repair, before discharge, and the latest follow-up findings based on a Doppler sonographic study

\begin{tabular}{lccc}
\hline MR (degree) & $\begin{array}{c}\text { Before } \\
\text { operation }(n)\end{array}$ & $\begin{array}{c}\text { Before } \\
\text { discharge }(n)\end{array}$ & $\begin{array}{c}\text { Most recent } \\
\text { follow-up }(n)\end{array}$ \\
\hline Severe & 3 & 0 & 0 \\
Moderate & 13 & 0 & 0 \\
Mild & 0 & 0 & 1 \\
None-trivial & 0 & 16 & 15 \\
\hline
\end{tabular}

against the muscle. When the prolapsed portion was wide, then another ePTFE suture was placed in the same fashion. Bilateral (10 patients) or unilateral (6 patients) Kay-Reed annuloplasty was added according to the dilatation of the mitral anulus. The diameter of the anulus was reduced to normal size, according to the publication of Rowlatt and colleagues. ${ }^{15}$

Cold cardioplegic solution was then injected into the left ventricular cavity again to assess valve competence. The repair was considered acceptable when the regurgitation was less than trivial during this test.

Follow-up. Before being discharged, all patients under-
Table III. Clinical data before and after mitral valve repair

\begin{tabular}{lccc}
\hline & $\begin{array}{c}\text { Before the } \\
\text { operation } \\
( \pm S E)\end{array}$ & $\begin{array}{c}\text { At follow-up } \\
( \pm S E)\end{array}$ & P value \\
\hline LVDd (\% normal) $^{*}$ & $128 \pm 4.0$ & $95 \pm 2.0$ & $<.0001$ \\
LVDs (\% normal) & $127 \pm 5.0$ & $96 \pm 5.0$ & $<.0001$ \\
Mitral annular dimension & $3.6 \pm 0.6$ & $0.7 \pm 0.6$ & $<.0001$ \\
(Z-value) $^{*}$ & & & \\
\hline
\end{tabular}

*Evaluated by echocardiography performed before the operation and during the recent follow-up period.

went several echocardiograms to assess the adequacy of the repair. A complete follow-up was achieved in all cases at the Fukuoka Children's Hospital by a clinical examination and serial echocardiograms.

Statistical analysis. Computerized statistical analysis was performed with the StatView 5.0 for Macintosh statistical program (Abacus Concepts, Inc, Berkeley, Calif). All values are expressed as the mean \pm SEM. Friedman tests were used to analyze continuous data. To analyze the change of other variables, a paired $t$ test was performed. 


\section{Results}

No operative death or morbidity was observed. Before they were discharged from the hospital, echocardiography was performed in all patients. These results revealed trivial $\mathrm{MR}$ in 5 patients and none in the remaining 11 patients (Table II).

No late death or reoperation occurred during the follow-up period (range, 1.3-26.4 months; median, 14.8 months). Anticoagulation was performed with warfarin sodium and aspirin sulfate during the first 3 months after the operation. There were no episodes of hemorrhage or thromboembolism. No progressive MR was seen that was more than mild, and the LVDd, LVDs, and mitral annular diameter all decreased in all patients based on the echocardiographic findings obtained during the follow-up period (Table III). The time course of the degree of MR was significantly different $(P<$ .0001). Especially, the degrees of MR before discharge and during follow-up were significantly lower than the data obtained before the operation $(P<.0001$ and $P=$ .0002 , respectively). However, no significant differences were observed between before discharge and follow-up $(P=.289)$.

\section{Discussion}

Incompetence of the mitral valve may be treated surgically by valve reconstruction or by valve replacement. MVR is a well-established and safe procedure in adults; however, it is generally accompanied with various difficulties in infants and children, such as valvular dysfunction, required anticoagulation, and re-replacement of the prosthetic valve because of patient somatic growth. As a result, several reports have corroborated that MVR in infants and children is associated with the risk of death and morbidity. ${ }^{1,5,16-18}$

Several reports have shown acceptable results of mitral valve repair in children with MR, with an actuarial survival of $82 \%$ at 5 years and an actuarial freedom from reoperation of $83 \%$ at 8 years (Aharon and colleagues $^{3}$ ), $88 \%$ and $67.7 \%$ at 15 years (Chauvaud and colleagues $^{5}$ ), and $88.4 \%$ and $86 \%$ at 17 years (Okita and colleagues $^{2}$ ). In our experience between 1982 and 1997, 50 children with MR underwent mitral valve operations. Our results were comparable with other reports, with an actuarial survival at 15 years of $85 \%$ and freedom from reoperation at 15 years of $70 \%$. However, before we had introduced the chorda reconstruction technique with artificial chordae in 1994, operative results for the repair of mitral valve in 20 cases with anterior leaflet prolapse were unsatisfactory, with 1 operative death, 4 reoperations, and 2 late deaths. After the introduction of the chorda reconstruction technique, 16 patients with ante- rior leaflet prolapse underwent mitral repair with a $100 \%$ success rate, with no operative mortality, no reoperation, and no late deaths. ${ }^{6}$

Results of the triangular resection technique of the anterior leaflet remain unsatisfactory. ${ }^{3,19}$ Because the amount of the anterior leaflet must be restricted to the relatively small excess segment in small children, the relevant anulus cannot be plicated, and a distortion of the coaptation line sometimes occurs when this technique is used. ${ }^{19}$ The chordal transfer technique is an attractive procedure with reported good results. ${ }^{5}$ However, this procedure is technically demanding, especially in small children, and not always possible when the posterior leaflet is not normal. ${ }^{9,12,19}$ The technique of chordal shortening by suturing the elongated chordae to the papillary muscle has been abandoned because of a high rate of recurrent elongation or rupture of shortened chordae. ${ }^{12,19}$ On the other hand, although the early results of another technique of chordal shortening by replacing them with glutaraldehyde-treated xenograft or autologous pericardial strip were found to be acceptable in some reports, ${ }^{7,19}$ these materials thickened and lost some of their pliability during the follow-up. ${ }^{7-9}$

In contrast, mitral valve repair by reconstruction of the chordae tendineae with ePTFE sutures is now widely accepted in experimental models ${ }^{8}$ and in adult patients because of its reproducibility and excellent functional long-term results. ${ }^{11-12}$ In adult patients, this technique has now become the procedure of choice especially for repairing a prolapsed anterior mitral leaflet caused by chordal abnormalities.

For a successful repair with the use of this technique, the most important factor is accurately determining the proper length of the reconstructed chordae. Especially in children, this factor is even more important because of the small leaflet size. During this procedure, many surgeons tie the suture at the leaflet level while the opposite leaflet is kept taut. ${ }^{7-11,20}$ With this method, it is difficult for a surgeon to know the precise length of the new chordae while he ties the sutures, because the leaflets may disturb his direct vision of the new chordae and the mitral apparatus under the leaflets. However, our method of determining the length described herein can be performed under good and direct vision and is more easily applicable to younger patients than other previously reported methods. ${ }^{7-11,20}$ When the length of the ePTFE sutures is not proper and significant regurgitation remains, fresh sutures must be applied to replace the previous sutures.

There is a possibility that MR will recur in the future because the reconstructed artificial chordae have no 
growth potential. At the same time, we can expect that the compensatory growth of papillary muscles or leaflets can be expected to result in good valve function in the future. ${ }^{21}$ Even when reoperation seems to be unavoidable for mitral incompetence, it is simple to place additional artificial chordae. In cases requiring MVR, we can also use a larger-sized prosthetic valve, which can help reduce the risk of re-replacement. Furthermore, as the patients age, we can easily induce and maintain adequate anticoagulation. Because the risk of valve replacement and the rate of reoperation is high in infants and young children, ${ }^{16-18}$ this repair may be especially beneficial to such patients.

\section{Conclusion}

In MR in children, reconstruction of the chordae tendineae with ePTFE sutures is considered to be a safe and useful procedure, and the indications for this technique may also be extended for mitral valve repair. Because our experience is limited to only 16 patients and the follow-up is too short to make any definitive conclusions, further investigation is required to evaluate the long-term results of this procedure.

We thank Naoko Kinukawa for her help with the statistical analysis.

\section{REFERENCES}

1. Carpentier A, Branchini B, Cour JC, Asfaou E, Villani M, Deloche A, et al. Congenital malformations of the mitral valve in children: pathology and surgical treatment. J Thorac Cardiovasc Surg 1976;72:854-66.

2. Okita Y, Miki S, Kusuhara K, Ueda Y, Tahata T, Tsukamoto Y, et al. Early and late results of reconstructive operation for congenital mitral regurgitation in pediatric age group. J Thorac Cardiovasc Surg 1988;96:294-8.

3. Aharon AS, Laks H, Drinkwater DC, Chugh R, Gates RN, Grant $\mathrm{PW}$, et al. Early and late results of mitral valve repair in children. J Thorac Cardiovasc Surg 1994;107:1262-71.

4. Sousa Uva M, Galletti L, Lacour Gayet F, Piot D, Serraf A, Bmniaux J, et al. Surgery for congenital mitral valve disease in the first year of life. J Thorac Cardiovasc Surg 1995;109:164-76.

5. Chauvaud S, Fuzellier JF, Houel R, Berrebi A, Mihaileanu S, Carpentier A. Reconstructive surgery in congenital mitral valve insufficiency (Carpentier's techniques): long-term results. J Thorac Cardiovasc Surg 1998;115:84-93.

6. Masuda M, Kado H, Imoto Y, Siokawa Y, Fukae K, Kanegae Y, et al. Clinical results of mitral valve surgery in children. [in Japanese]. Jpn J Thorac Surg1999;52:301-6.

7. Frater RWM, Vetter HO, Zussa C, Dahm M. Chordal replacement in mitral valve repair. Circulation 1990;82(Suppl):IV125-30.

8. Revuelta JM, Garcia-Rinaldi R, Gaite L, Val F, Garijo F. Generation of chordae tendineae with polytetrafluoroethylene stent. J Thorac Cardiovasc Surg 1989;97:98-103.

9. David TE, Bos J, Rakowski H. Mitral valve repair by replacement of chordae tendineae with polytetrafluoroethylene sutures. J Thorac Cardiovasc Surg 1991;101:495-501.

10. Zussa C, Polesel E, Da Col U, Galloni M, Valfre C. Seven-year experience with chordal replacement with expanded polytetrafluoroethylene in floppy mitral valve. J Thorac Cardiovasc Surg 1994;108:37-41.

11. David TE, Omran A, Armstrong S, Sun Z, Ivanov J. Longterm results of mitral valve repair for myxomatous disease with and without chordal replacement with expanded polytetrafluoroethylene sutures. J Thorac Cardiovasc Surg 1998;115:1279-86.

12. Eishi K, Kawazoe K, Nakano K, Kosakai Y, Sasako Y, Kobayashi J. Long-term results of artificial chordae implantation in patients with mitral valve prolapse. J Heart Valve Dis 1997;6:594-8.

13. Fukushige J. Echocardiography in normal infants and children [in Japanese]. Jpn Circ J 1980;44(suppl):351-62.

14. Kirklin JW, Barratt-Boyes BG. Anatomy, dimensions, and terminology. In: Kirklin JW, Barratt-Boyes BG, editors. Cardiac surgery. 2nd ed. New York: Churchill Livingstone; 1993. p. 3-60.

15. Rowlatt JF, Rimoldi JHA, Lev M. The quantitative anatomy of the normal child's heart. Pediatr Clin North Am 1963;10:499-588.

16. Kadoba K, Jonas RA, Mayer JE, Castaneda AR. Mitral valve replacement in the first year of life. J Thorac Cardiovasc Surg 1990;100:762-8.

17. Zweng TN, Bluett MK, Mosca R, Callow LB, Bove EL. Mitral valve replacement in the first 5 years of life. Ann Thorac Surg 1989;47:720-4.

18. Fiane AE, Lindberg HL, Saatvedt K, Svennevig JL. Mechanical valve replacement in congenital heart disease. J Heart Valve Dis 1996;5:337-42.

19. Eishi K, Kawazoe K, Sasako Y, Kosakai Y, Kitoh Y, Kawashima Y. Comparison of repair techniques for mitral valve prolapse. J Heart Valve Dis 1994;3:432-8.

20. Kasegawa H, Kamata S, Hirata S, Kobayashi N, Mannouji E, Ida $\mathrm{T}$, et al. Simple method for determining proper length of artificial chordae in mitral valve repair. Ann Thorac Surg 1994;57:237-9.

21. Murakami T, Yagihara T, Yamamoto F, Uemura H, Yamashita K, Ishizaki T. Artificial chordae for mitral valve reconstruction in children. Ann Thorac Surg 1998;65:1377-80. 